UJMR, Volume 5 Number 2, December, 2020, pp 123 - 130 ISSN: 2616 - 0668

Received: $21^{\text {st }}$ December, $2020 \quad$ Accepted: $23^{\text {rd }}$ December, 2020

https://doi.org/10.47430/ujmr.2052.017

\title{
Prevalence of Multidrug Resistant Escherichia Coli In Suspected Cases of Urinary Tract Infection Among Patients Attending Ahmadu Bello University Medical Center, Zaria
}

\author{
*Shitu, S., Gambo, B. A., Musa, M.O., Abubakar, A.A. and Attahiru, M. \\ Department of Applied Biology, \\ College of Science and Technology, \\ Kaduna Polytechnic, Kaduna State, Nigeria \\ *Corresponding Author; E-mail: sabiushitu22@gmail.com\&sabiushitu@kadunapolytechnic.edu.ng
}

\begin{abstract}
Urinary tract infections (UTIs) are a major health problem, the second most prevalent human bacterial infection after respiratory tract infection. Patient with urinary tract infection is a potential source of multi drug resistant (MDR) Escherichia coli $(E$. coli) with the potentials to spread antimicrobial resistant genes to other bacteria in the environment and other human populations. The aim of the study was to isolate and determine the prevalence of MDR Escherichia coli from patients suspected with urinary tract infection attending Ahmadu Bello University Medical Center, Zaria. A total of 95 urine samples were collected and processed according to standard microbiological methods for the isolation and identification of $E$. coli. Antibacterial susceptibility pattern of the isolates was determined using Kirby-Bauer's disk diffusion technique as well as MAR indices. Out of the 95 urine samples collected 32 were from males and 63 were from females, whose ages were between 5 and 74 years. The results revealed that $35(36.8 \%)$ out of the 95 samples collected were positive for $E$. coli with high prevalence among the female patients $23(24.2 \%)$ compared to the male patients $12(12.4 \%)$. High prevalence of $E$. coli was also reported among the patients within the age ranges of 15-24 and 25-34 years. The Escherichia coli isolates demonstrated high resistance to sparfloxacin (91.4\%), followed by cotrimoxazole and amoxicillin $(82.9 \%)$. Additionally, $30(85.7 \%)$ of the isolates exhibited multi drug resistance and $94.3 \%(n=33 / 35)$ had a MAR index above 0.2 . The study demonstrated that some of the $E$. coli isolates in the study are from high-risk contaminated sources where there may be high frequency of antibiotic usage. Therefore, the study indicated the need for Physicians to prescribed antibiotics to patients following standard antibacterial susceptibility testing.

Keywords: Prevalence, Escherichia coli, Multi drug resistant, Urinary tract infection
\end{abstract}

\section{INTRODUCTION}

Urinary tract infections (UTIs) are usually caused by bacteria, although they may also be caused by fungi and certain viruses. Gramnegative bacteria from the Enterobacteriaceae family, including Escherichia coli are among the bacteria. Most of those involved are E. coli, Klebsiella, Enterobacter, Proteus bacteria, among others (Foxman and Brown, 2003). However, particularly among young women, some Gram-positive bacteria, mainly Staphylococcus aureus, Staphylococcus saprophyticus and Streptococcus agalactiae, also play a role. In all patient classes, Escherichia coli is the dominant causative agent that triggers $80-90 \%$ of all urinary tract infections (Foxman et al., 2000).

Escherichia coli is a natural component of the human and animal intestinal microbiota (Ruiz et al., 2002; Zhang and Foxman, 2003). The distinctive $E$. coli strains that cause most UTIs have been identified uropathogenic $E$. coli (UPEC) (Johnson et al., 2005). They have numerous virulence-related factors (VFs) that assist them in binding, invading, and harming the host, including adhesins, toxins, siderophores, polysaccharide defensive coatings, invasins, and proteins associated with serum resistance (Johnson et al., 2005).

The use of antimicrobials among patients with suspected cases of urinary tract infection has led to the selection of resistant organisms, resulting in dissemination of drug-resistant bacteria (Wenzel et al., 2008; Szmolka and Nagy, 2013). The development of multidrug resistance (MDR; resistance to $\geq 2$ antimicrobials) to major classes of antimicrobials within a short period of time after approval for medical use is cause for concern, especially due to the time required to produce new antimicrobial agents (Walsh 2003; Frye and Jackson 2013). Urinary tract infections due to multi drug resistant (MDR) $E$. coli increases the cost of treatment, morbidity and mortality especially in developing countries (Williams et al., 2008; Al-jiffri et al., 2011). 
UJMR, Volume 5 Number 2, December, 2020, pp 123 - 130 ISSN: 2616 - 0668

Many of the resistances in MDR E. coli are located on plasmids, which increases the possibility of clonal dissemination of these resistance classes in the community (Williamson et al., 2013; Chen et al., 2014). Spread of MDR $E$. coli globally can also be attributed to clones, such as $E$. coli sequence type 131 (ST131), known for its resistance to fluoroquinolones, aminoglycosides and trimethoprimsulfamethoxazole, as well as its virulence and propensity to exchange genetic material, characteristics which further complicate therapy. A number of reports exist on the emergence of this clonal group in $E$. coli from the community and hospital infections in developed and developing countries (Lau et al., 2008; Rogers et al., 2011; Petty et al., 2014). In Nigeria, the emergence of $E$. coli ST131 and ST617 among clinical isolates of $E$. coli was reported in 2012 (Aibinu et al., 2012). However, there is a paucity of data from community infections in Nigeria on the MDR profile of $E$. coli and their genetic lineages or reports on the major clonal complex circulating in the community. The potential spread of MDR $E$. coli is significant, especially for developing countries, which may have low financial resources for healthcare systems and poor infection control management (Adenipekun et al., 2016).

To provide more information on the extent of MDR E. coli, the prevalence and antimicrobial resistance of $E$. coli among patients was determined. $E$. coli isolates in this study were tested against a wide range of broad-spectrum antimicrobials. In addition, data on the available antimicrobials that these bacterial organisms are already resistant to is required for proper diagnosis and treatment of bacterial infections in humans.

Experts recommend that the option of antibiotics should be based on the findings of a urine culture and susceptibility test in patients with suspected complicated UTI (Gupta et al., 2001; Scotish Intercollegiate Guidelines Network, 2015). This study aimed at determining prevalence of multidrug resistant Escherichia coli from urine of suspected urinary tract infection patients attending Ahmadu Bello University Medical Center, Zaria, Nigeria, in order to generate data that will support clinical decision-making as well as public health and safety.

MATERIALS AND METHODS

Samples collection

A total of ninety-five (95) urine samples were collected in sterilized universal containers following the approval from Ahmadu Bello University Medical Center, Zaria from April, 2019 to August, 2019. The study participants included 32 males and 63 female patients between the ages of 5 and 74 years with suspected cases of UTI. The early morning midstream urine samples collected aseptically in a wide mouthed container with screw cap tops, were properly labelled indicating the patients' age, sex, date, and time of collection. Then, the collected samples were transported in ice packs to the Department of Microbiology, Ahmadu Bello University, Zaria, Nigeria within 4-6hours of collection, for analysis.

\section{Sample processing}

The urine samples were cultured on MacConkey agar aseptically using a wire loop. The plates were incubated aerobically at $37^{\circ} \mathrm{C}$ for 24hours. After incubation, the cultures were examined for significant bacterial growth based on colonial morphology. The colonies appearing pink suspected to be Escherichia coli were picked and sub-cultured onto nutrient agar slants for isolation of pure colonies and then incubated at $37^{\circ} \mathrm{C}$ for 24 hours (Collee et al., 1996; Cheesbrough, 2006).

Identification of isolates

The isolates were identified based on colonial morphology, Gram staining reaction, confirmatory test and appropriate biochemical tests such as sugar fermentation test using Triple Sugar Iron Agar, oxidase test, indole test, methyl red test, Voges-Proskauer test, citrate utilization test and ONPG (Ortho-nitrophenyl Beta-D-galactopyranoside) test (Collee et al., 1996; Cheesbrough, 2006).

Antibiotics susceptibility testing

All isolates were tested for antibiotics susceptibility first by standardizing the inocula and then inoculating onto Mueller-Hinton agar by the Kirby-Bauer disc diffusion method (Bauer, 1966) recommended by the Clinical and Laboratory Standards Institute (CLSI, 2015). Antibiotics Disks containing Cotrimoxazole $(30 \mu \mathrm{g}), \quad$ Gentamicin $(30 \mu \mathrm{g})$, Ciprofloxacin $(30 \mu \mathrm{g})$, Chloramphenicol $(30 \mu \mathrm{g})$, Augmentin $(10 \mu g)$, Perfloxacin $(30 \mu g)$, Sparfloxacin $(30 \mu g)$, Streptomycin $(30 \mu \mathrm{g})$, Amoxicillin $(30 \mu \mathrm{g})$ and Ofloxacin $(10 \mu \mathrm{g})$ were used against the isolates. Escherichia coli, ATCC25922, was used as the quality control strain (Cheesebrough, 2006). Susceptibility test results were interpreted according to the criteria established by the (CLSI, 2015). The results were reported as sensitive, intermediate and resistant according to Clinical Laboratory Standards Institute (CLSI, 2015) guide lines. An isolate was defined as being multi-drug resistant, when it was found to be resistant to three or more of the antibacterial agents tested and based on the antimicrobial categories (Margiorakos et al., 2012). 
UJMR, Volume 5 Number 2, December, 2020, pp 123 - $130 \quad$ ISSN: 2616 - 0668

Determination of multiple antibiotic or equals to $0.05(\mathrm{p} \leq 0.05)$ were considered
resistance $(M A R)$ index

The multiple antibiotic resistance (MAR) index for each isolate was determined using the formula MAR $=a / b$, where ' $a$ ' is the number of antibiotics to which the test isolate was resistant to and ' $b$ ' is the total number of antibiotics to which the test isolates were subjected (Sandhu etal., 2016)

\section{Statistical analysis}

Data generated were analyzed using Chi-square analysis (SAS version 9.1.3). P -value less than

\section{RESULTS}

The result indicated that 60 (63.2\%) of the urine samples were negative and 35 (36.8\%) were positive for $E$. coli. Moreover, high prevalence cases were identified among patients between 25-34 and 15-24 age groups with $(46.2 \%)$ and $(40 \%)$ prevalence respectively (Table 1 ). The differences are not statistically significance $(P=0.497)$.

Table 1: Prevalence of Escherichia coli based on age group of patients

\begin{tabular}{llll}
\hline Age(Years) & No. Examined & No. Positive & Prevalence (\%) \\
\hline $5-14$ & 9 & 3 & 33.3 \\
$15-24$ & 25 & 10 & 40 \\
$25-34$ & 13 & 6 & 46.2 \\
$35-44$ & 33 & 12 & 36.4 \\
$45-54$ & 10 & 3 & 30 \\
$55-64$ & 0 & 0 & 0 \\
$65-74$ & 5 & 1 & 20 \\
Total & 95 & 35 & 36.8 \\
\hline
\end{tabular}

$\mathrm{P}=0.4971$

The prevalence of Escherichia coli according to gender of the patients reveals that 12 (37.5\%) males were positive while $23(36.5 \%)$ were female patients (Table 2 ). The highest prevalence of E. coli based on gender was observed in female patients. However, based on statistical analysis it was observed to be not significant $(P=0.9245)$.

Table 2: Prevalence of Escherichia coli based on gender of patients

\begin{tabular}{lccc}
\hline Gender & No. Examined & No. Positive & Prevalence (\%) \\
\hline Male & 32 & 12 & 37.5 \\
Female & 63 & 23 & 36.5 \\
Total & 95 & 35 & 36.8 \\
\hline
\end{tabular}

$P=0.9245$

The drug susceptibility pattern of the Escherichia coli isolates against the 10 different antibiotics was shown in Table 3. The findings of the study showed that $E$. coli was highly susceptible to augmentin (71.1\%) followed by gentamicin and chloramphenicol (68.6\%). However, the Escherichia coli isolates demonstrated high resistance to sparfloxacin $(91.4 \%)$, followed by cotrimoxazole and amoxicillin (82.9\%) and ciprofloxacin (71.4\%).

Table 3: Antibiotics susceptibility pattern of Escherichia coli isolates from urine samples

\begin{tabular}{ccc}
\hline $\begin{array}{c}\text { Antibiotics (disk } \\
\text { conc. in } \mu \mathrm{g})\end{array}$ & \multicolumn{2}{c}{ Susceptibility of $E$. coli $(\mathbf{n}=35)$} \\
& Sensitive (\%) & Resistant (\%) \\
\hline SXT (30) & $6(17.1)$ & $29(82.9)$ \\
CH (30) & $24(68.6)$ & $11(31.4)$ \\
SP (10) & $3(8.6)$ & $32(91.4)$ \\
CPX (30) & $10(28.6)$ & $25(71.4)$ \\
AM (30) & $6(17.1)$ & $29(82.9)$ \\
AU (10) & $25(71.1)$ & $10(28.6)$ \\
GN (30) & $24(68.6)$ & $11(31.4)$ \\
PEF (30) & $8(22.9)$ & $27(77.1)$ \\
OFX (10) & $12(34.3)$ & $23(65.7)$ \\
S (30) & $21(60)$ & $14(40)$ \\
\hline
\end{tabular}

Key: $\mathrm{n}=$ number of isolates, SXT = Cotrimoxazole, $\mathrm{CH}=$ Chloramphenicol, $\mathrm{SP}=$ Sparfloxacin, $\mathrm{CPX}=$ Ciprofloxacin, $\mathrm{AM}=$ Amoxacillin, $\mathrm{AU}=$ Augmentin, $\mathrm{GN}=$ Gentamicin, $\mathrm{PEF}=$ Perfloxacin, $\mathrm{OFX}=$ Ofloxacin, S =Streptomycin. 
UJMR, Volume 5 Number 2, December, 2020, pp 123 - 130 ISSN: 2616 - 0668

Figure 1 describes the prevalence of MDR E. coli, a total of 30 (85.7\%) isolates were found to be MDR E. coli. While Table 4 present resistance patterns and multiple antibiotic resistance index. This study observed that $94.3 \%(n=33 / 35)$ of the isolates had multiple antibiotic resistance (MAR) index greater than 0.2 while $5.7 \%(n=2 / 35)$ isolates had MAR index of 0.2 .

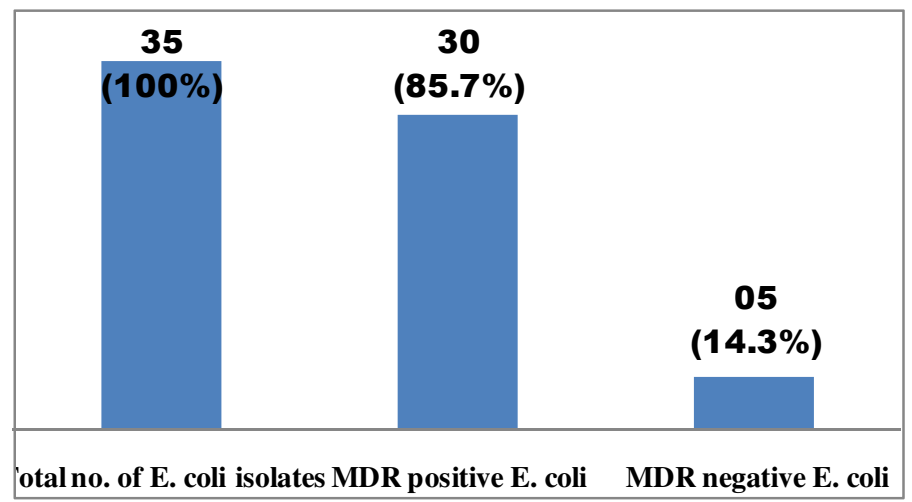

Figure 1: Prevalence of Multi drug resistant (MDR) Escherichia coli from urine samples of suspected urinary tract infection patients attending Ahmadu Bello University Medical Center, Zaria.

Table 4: Antibiotic resistance pattern and MAR Index in Escherichia coli isolates

\begin{tabular}{|c|c|c|c|}
\hline $\mathrm{S} / \mathrm{N}$ & Isolate Code & Resistance pattern & MAR Index \\
\hline 1 & AMC3 & SXT, SP, AM, AU,PEF, OFX & 0.6 \\
\hline 2 & AMC 5 & $\mathrm{CH}, \mathrm{CPX}, \mathrm{AM}, \mathrm{PEF}, \mathrm{S}$ & 0.5 \\
\hline 3 & AMC 6 & SXT,SP,AM,PEF,OFX & 0.5 \\
\hline 4 & AMC 8 & SXT, CH,SP,AM,AU,PEF,OFX & 0.7 \\
\hline 5 & AMC 11 & STX,SP,CPX,AM,PEF,S & 0.6 \\
\hline 6 & AMC 21 & SXT,CH,SP,CPX,AM,AU, GN,PEF,OFX & 0.9 \\
\hline 7 & AMC 25 & $\mathrm{SP}, \mathrm{CPX}, \mathrm{S}$ & 0.3 \\
\hline 8 & AMC 27 & SXT,CH,SP,CPX,AM,PE, OFX,S & 0.8 \\
\hline 9 & AMC 28 & SXT,SP,CPX,AU, PEF,OFX & 0.6 \\
\hline 10 & AMC 32 & SXT, CH,CPX,AM,PEF,S & 0.6 \\
\hline 11 & AMC 38 & SXT,SP,CPX,AM, GN, OFX & 0.6 \\
\hline 12 & AMC 40 & $\mathrm{SXT}, \mathrm{CH}, \mathrm{SP}, \mathrm{CPX}, \mathrm{AM}, \mathrm{AU}, \mathrm{GN}, \mathrm{PEF}, \mathrm{OFX}$ & 0.9 \\
\hline 13 & AMC 41 & SXT,SP,CPX, & 0.3 \\
\hline 14 & AMC 42 & SXT,CH,SPAM,AU, GN,OFX & 0.7 \\
\hline 15 & AMC 44 & SP,CPX,AM,PEF, OFX,S & 0.6 \\
\hline 16 & AMC 47 & SXT,CH,SP,CPX,AM,PEF & 0.6 \\
\hline 17 & AMC 49 & SXT,SP,AM,AU,GEN,OFX & 0.6 \\
\hline 18 & AMC 50 & SXT,CH,SP,CPX,AM,PEF,S & 0.7 \\
\hline 19 & AMC 51 & SXT,SP,CPX,AM,PEF,OFX & 0.6 \\
\hline 20 & AMC 53 & $\mathrm{CH}, \mathrm{SP}, \mathrm{AM}, \mathrm{AU}, \mathrm{GN}, \mathrm{OFX}, \mathrm{S}$ & 0.7 \\
\hline 21 & AMC 58 & SXT,SP,CPX,AM,PEF,OFX & 0.6 \\
\hline 22 & AMC 61 & SXT, SP, CPX,AM,AU, GN,PEF, OFX,S & 0.9 \\
\hline 23 & AMC 63 & SP,AM & 0.2 \\
\hline 24 & AMC 64 & SXT,CH,SP,AM,GN,OXF,S & 0.7 \\
\hline 25 & AMC 66 & SXT,SP,CPX,AM,PEF & 0.5 \\
\hline 26 & AMC 69 & SXT, SP, CPX, GN,PEF, OFX,S & 0.7 \\
\hline 27 & AMC 70 & CPX,AM & 0.2 \\
\hline 28 & AMC 71 & SXT,SP,CPX,AU,GN,OFX,S & 0.7 \\
\hline 29 & AMC 74 & SXT,SP,CPX,AM,PEF,OFX & 0.6 \\
\hline 30 & AMC 75 & SXT, SP,CPX,AM, GN,OFX,S & 0.7 \\
\hline 31 & AMC 79 & SXT,SP,CPX,AM,PEF,OFX & 0.6 \\
\hline 32 & AMC 83 & SXT, SP, CPX,AM, GN,PEF, OFX,S & 0.8 \\
\hline 33 & AMC 86 & SXT,SP,AM,GN,PEF & 0.5 \\
\hline 34 & AMC 90 & SXT,SP,PEF & 0.3 \\
\hline 35 & AMC 92 & SXT,SP,CPX,AM, GN,PEF,OFX & 0.7 \\
\hline
\end{tabular}

Key: $\mathrm{AMC}=$ Ahmadu Bello University Medical Centre, $\mathrm{AMR}=$ Multiple Antibiotic Resistant, $\mathrm{SXT}=$ Cotrimoxazole, $\mathrm{CH}=$ Chloramphenicol, $\mathrm{SP}=$ Sparfloxacin, $\mathrm{CPX}=$ Ciprofloxacin, $\mathrm{AM}=$ Amoxacillin, $\mathrm{AU}=$ Augmentin, $\mathrm{GN}=$ Gentamicin, $\mathrm{PEF}=$ Perfloxacin, OFX = Ofloxacin, $\mathrm{S}=$ Streptomycin.

UMYU Journal of Microbiology Research 


\section{DISCUSSION}

The findings of this study reveal that the prevalence of $E$. coli among the studied subjects was $36.8 \%$. This implies that a significant number of patients suspected with UTI may harbour $E$. coli. This observation may not be unconnected with the fact that $E$. coli is a natural component of the human and animal intestinal microbiota as documented by Ruiz et al. (2002); Zhang and Foxman (2003), however its presence in the urine samples of the studied subject who were patients suspected with UTIs is a source of concern.

Compared to the findings of this study, Aboderin et al. (2009) reported lower prevalence of $E$. coli of $25.6 \%$, Karuiki et al. (2007), reported $36 \%$ in Nairobi, Kenya. Sanitary conditions as well as hygiene practices among patients may have accounted for the disparity in the prevalence observed.

In line with the observation of studies by Eghieye et al. (2018); Farouk et al. (2019), this study also revealed that the prevalence of Escherichia coli was higher among those aged 15-24 years and 25-34 years. The high prevalence of $E$. coli in these age groups may be related to the fact that patients in this age group are sexually active and possibly to have been infected with uropathogenic $E$. coli.

In terms of gender, the prevalence of $E$. coli was found to be higher in females than it was in males. This is similar with the findings of Eghieye et al, 2018 and Farouk et al., 2019. The near proximity of the urogenital tract to the anus in women may account for the higher percentage observed among women, makes it possible for Escherichia coli, typically located in the gastrointestinal system, to be conveyed to the female genital tract (Ovalle and Levancini, 2001). The lower prevalence $E$. coli detected in men may be due to the greater length of the male urethra and the antibacterial activity of male prostatic fluid (Gupta and Stamm, 2005).

The study demonstrated that almost all the $E$. coli isolates obtained in the study were resistant to two or more antibiotics with $85.7 \%$ of them identified as MDR. This observation demonstrated that $E$. coli isolated in the study were highly resistant and is a source of public health concern.

This high degree of resistance found in $E$. coli could be attributed to the indiscriminate use of antibiotics, over-prescription, poor quality and cheaper medicines that are being marketed and delivered to patients that do not have urinary tract infection (Batabyal and Himanshu, 2018). In a study, Szmolka and Nagy (2013) noted that drug resistant commensal $E$. coli remains a reservoir of drug resistance and may also be responsible for the resistance pattern observed in their study.

Similar to the reports of this study, other studies on the prevalence and risk factors for multi-drug resistant Escherichia coli among poultry workers in the Federal Capital Territory, Abuja, Nigeria, reported $81.3 \%$ prevalence of MDR E. coli (Kamweli et al., 2019). Another survey of households and chicken farms in the Mekong Delta in Vietnam reported a high prevalence of multidrug resistant E. coli (81.3\%) (Campbell et al., 2015). However, some studies revealed lower prevalence of MDR $E$. coli. For instance, a study done in Korea among poultry farm workers reported that $43 \%$ of $E$. coli isolated from the workers showed resistance to four or more antimicrobials used in poultry production (Cho et al., 2012). Similarly, another study in the Netherlands reported that $27 \%$ of $E$. coli isolated from broiler and layer chicken farmers showed resistance to more than three antimicrobials (Bogaard, 2009).

It has been documented that multiple antibiotic resistance is mostly observed by the action of multidrug efflux pumps, each of which can pump out more than one drug type (Nikaido et al., 2009).

The findings of this study showed that $94.3 \%$ of $E$. coli isolates had MAR index greater than 0.2. Studies have shown that MAR indices greater than 0.2 implies isolates from high-risk contaminated sources with frequency of antibiotic use (Thenmozhi et al., 2014). This may be correlated with the indiscriminate use of antimicrobials among patients with suspected UTI for therapy purposes.

The findings of this study also demonstrates that the $E$. coli isolates obtained from the urine of patients with suspected UTI showed high resistance rates against sparfloxacin (91.43\%), cotrimoxazole $(82.86 \%)$ and amoxicillin $(82.86 \%)$, ciprofloxacin $(71.43 \%)$ and ofloxacin $(65.71 \%)$. However, few of the isolates were found to be susceptible to other antibiotics, particularly streptomycin, augmentin, gentamicin and chloramphenicol. A similar study in Nigeria reported high resistance rates against amoxicillin, cotrimoxazole and ciprofloxacin (Sabir et al., 2014; Namrathan, 2015; Farouk et al., 2019). A possible explanation for MDR $E$. coli observed among the patients may be due to the widespread use and easy availability of these drugs, which has led to the high resistance pattern of the isolates. 
UJMR, Volume 5 Number 2, December, 2020, pp 123 - 130 ISSN: 2616 - 0668

CONCLUSION

The study has observed a high prevalence rate of MDR E. coli (85.7\%) among patients with suspected cases of urinary tract infection attending Ahmadu Bello University Medical Center, Zaria. The Escherichia coli isolates demonstrated high resistance to sparfloxacin $(91.4 \%)$, followed by cotrimoxazole and amoxicillin (82.9\%). The prevalence of MDR Escherichia coli isolates with MAR indices greater than 0.2 is a threat to the ongoing campaign against antibiotic misuse.

\section{REFERENCES}

Aboderin, O. A., Abdu, A. R., Odetoyin, B. W. and Lamikanra, A. (2009). Antimicrobial resistance in Escherichia coli strains from urinary tract infections. Journal of the national medical association, 101(12), 1268-1273.

Aibinu, I., Odugbemi, T., Koenig, W. and Ghebremedhin, B. (2012). Sequence type ST131 and ST10 complex (ST617) predominant among (TX-M-15producing Escherichia coli isolates from Nigeria. Clinical Microbiology Infection 18: E49-E51.

Al-jiffri, O., Zahira, M. F., El-Sayed, F. and AlSharif, M. (2011). Urinary Tract Infection with $E$. coli and antibacterial activity of some plant extract. International Journal of Microbiology Research. 2:1-7.

Arredondo-Garcia, J. L. and Amabile-Cuevas, C.F. (2008). High resistance prevalence towards ampicillin, cotrimoxazole and ciprofloxacin, among uropathogenic Escherichia coli isolates in Mexico City. Journal of Infection in Developing Countries. 2:350-353.

Babalola, O. O. and Lamikanra, A. (2002). Pattern of antibiotic purchases in community pharmacies in South Western Nigeria. Journal of Social and AdministrativePharmacy.19:33 - 38.

Batabyal, B. and Himanshu (2018). Isolation and antimicrobial resistance patterns of Escherichia coli causing urinary tract infections in children aged 1 to 12 years. Journal of Bacteriol Infec Dis.2 (1):35-42.

Bauer, A.W., Kirby, W. M., and Sherris, J. C. (1966). Antibiotic susceptibility testing by a standardized single disk method. American Journal of Clinical Pathology; 45(4):493-6.

Bogaard, V. A. E. (2001). Antibiotic resistance of faecal Escherichia coli in poultry, poultry farmers and poultry slaughterers. Journal of Antimicrobial Chemo therapy. 47: 763-771.

UMYU Journal of Microbiology Research
Therefore, strict measures in the administration of antibiotics should be adhered to by Clinicians in the treatment of urinary tract infection and drugs should only be prescribed following antibiotic sensitivity testing of the isolates.

\section{ACKNOWLEDGEMENT}

The author acknowledges the Management, Ahmadu Bello University Medical Center, Zaria, for granting approval for the study.

https: / /doi.org/10.1093/jac/47.6.763 PMID: 11389108

Campbell, J. I., Nhung, N. T., Nhung, H. N., Van Minh, P. and Wagenaar, J. A. (2015). Prevalence and risk factors for carriage of antimicrobial-resistant Escherichia coli on household and small-scale chicken farms in the Mekong Delta of Vietnam. 2: 144-2152. https: / / doi.org/10.1093/jac/dkv053 PMID: 25755000.

Caudell, M. A., Mair, C., Subbiah, M., Matthews, L., Quinlan, R. J. and Quinlan, M. B. (2018). Articles Identification of risk factors associated with carriage of resistant Escherichia coli in three culturally diverse ethnic groups in Tanzania: a biological and socioeconomic analysis. 2: e489-e497. https:// doi.org/10.1016/S25425196(18)30225-0 PMID: 30396440.

Cheesbrough, M. (2006). District laboratory practice in tropical countries, part 2. Cambridge university press. Pp132-234.

Chen, X., He, L., Li, Y., Zeng, Z., Deng, Y., Liu, Y. and Liu, J. H. (2014). Complete sequence of a F2: A-: B- plasmid pHN3A11 carrying rmtB and qepA, and its dissemination in China. Vet Microbiol 174: 267-271.

Cho, S. H., Lim, Y. S. and Kang, Y. H. (2012). Comparison of Antimicrobial Resistance in Escherichia coli Strains Isolated from Healthy Poultry and Swine Farm Workers Using Antibiotics in Korea. Osong Public Heal Res Perspect.; 3: 151-155.

https: //doi.org/10.1016/j.phrp.2012.0 7.002 PMID: 24159507.

Collee, J. G., Duguid, J. P. and Fraser, A. G. (1996). Laboratory strategy in diagnosis of infective syndromes. In: Mackie and McCartney Practical Medical Microbiology, 14th ed. London: Churchill Livingstone.:53-94.

Eghieye, M. O., Jodi, S. M., Bassey, B. E., Nkene, I. H., Abimiku, R. H. and Ngwai, Y. B. (2018). Antimicrobial Resistance 
UJMR, Volume 5 Number 2, December, 2020, pp 123 - 130 ISSN: 2616 - 0668

Profile of Escherichia coli Isolated from Urine of Patients in Selected General Hospitals in Abuja Municipal, Nigeria. Asian Journal of Advanced Research and Reports, 2(2): 1-10,

Farouk, S. N., Muhammad, A., Muhammad, S. A. and Abubakar, U. Z. (2019). Prevalence and Antibiotic Susceptibility Pattern of Escherichia coli Isolated from Urine Samples of Urinary Tract Infection Patients. ARC Journal of Urology, (4)1:14-20.

Foxman, B., Barlow, R., D’Arcy, H., Gillespie, B. and Solbel, J. (2000). Urinary tract infection: Self-reported incidence and associated costs. Annals of Epidemiology; 10:509-515

Foxman, B. and Brown, P. (2003). Epidemiology of urinary tract infections: Transmission and risk factors, incidence, and costs. Infectious Disease Clinics of North America; 17:227-241

Frye, J. G. and Jackson, C. R. (2013). Genetic mechanisms of antimicrobial resistance identified in Salmonella enterica, Escherichia coli, and Enterococcus spp. isolated from U.S. food animals. Front Microbiology 4: 1-22.

Gales, A. C., Jones, R. N., Gordon, K. A., Sader, H. S., Wilke, W. W., Beach, M. L. and SENTRY Study Group Latin America, T. (2000). Activity and spectrum of 22 antimicrobial agents tested against urinary tract infection pathogens in hospitalized patients in Latin America: report from the second year of the SENTRY antimicrobial surveillance program (1998). Journal of Antimicrobial Chemotherapy, 45(3), 295-303.

Gupta, K., Sahm, D. F. and Mayfield, D. (2001). Antimicrobial resistance among uropathogens that cause communityacquired urinary tract infections in women: a nationwide analysis. Clinical Infectious Diseases. 33:89-94.

Gupta, K. and Stamm, W. E. (2005). Urinary tract infections. In: Dale DC, Federman DD, editors. ACP Medicine. New York: WebMD. Section 7, Chap. 23.

Hima-Lerible, H., Ménard, D. and Talarmin, A. (2003). Antimicrobial resistance among uropathogens that cause communityacquired urinary tract infections in Bangui, Central African Republic. Journal of Antimicrobial Chemotheraphy.51:192-194.

http://www.facm.ucl.ac.be/intranet/CLSI/CLSI -2015-M100-S25-original.pdf

Johnson, J. R., Kuskowski, M. A., O'Bryan, T. T., Colodner, R. and Raz, R. (2005).

UMYU Journal of Microbiology Research
Virulence genotype and phylogenetic origin in relation to antibiotic resistance profile among Escherichia coli urine sample isolates from Israeli women with acute uncomplicated cystitis. Antimicrobial agents and chemotherapy, 49(1), 26-31.

Kariuki, S., Revathi, G., Corkill, J., Kiiru, J., Mwituria, N. and Hart, C. A. (2007). Escherichia coli from communityacquired urinary tract infections resistant to fluoroquinolones and extended-spectrum beta-lactams. Journal of Infection in Developing Countries.1:257-262.

Kamweli, M. A., Kwaga, J., Okolocha, J., Mba, N. and Thaku, S. (2019). Prevalence and risk factors for multi-drug resistant Escherichia coli among poultry workers in the Federal Capital Territory, Abuja, Nigeria. PLOS ONE 14(11): e0225379. https://doi. org/10.1371/journal. pone.0225379.

Lau, S. H., Kaufmann, M. E., Livermore, D. M., Woodford, N., Willshaw, G. A., Cheasty, T., Stamper, K., Reddy, S., Cheesbrough, J., Bolton, F. J., Fox, A. J. and Upton, M. (2008). UK epidemic Escherichia coli strains A-E, with CTXM-15 beta-lactamase, all belong to the international 025:H4-ST131 clone. J Antimicrob Chemo ther 62: 1241-1244.

Margiorakos, A. P., Srinivasan, A., Carey, R. B., Carmeli, Y. and Falagas, M. E., (2012). Multi-drug resistant, extensively drug resistant and pan drug-resistant bacteria: An international expert proposal for interim standard definition for acquired resistance. Clinical Microbiology Infection. 18(3), 268-281.

Manges, A. R., Natarajan, P., Solberg, O. D., Dietrich, P. S. and Riley, L. W. (2006). The changing prevalence of drugresistant Escherichia coli clonal groups in a community: evidence for community outbreaks of urinary tract infections. Epidemiology Infection, 134(2), 425-431.

Manges, A. R., Tabor, H., Tellis, P., Vincent, C., and Tellier, P. P. (2008). Endemic and epidemic lineages of Escherichia coli that cause urinary tract infections. Emerging infectious diseases, 14(10), 1575.

Namrathan, W. N. (2015). Profile of urinary tract infection and quinolone resistances among Escherichia coli and Klebsellia species isolates. International Journal of Current Microbiology and Applied Sciences.; 4(7):749-756. 
UJMR, Volume 5 Number 2, December, 2020, pp 123 - $130 \quad$ ISSN: 2616 - 0668

Nikaido, H. (2009). Multidrug Resistance in Bacteria. Annual Review Biochemistry.; 78: 119-146. https: / / doi.org/10.1146/annurev.bioche m.78.082907.145923 PMID: 19231985

Ovalle, A. and Levancini, M. (2001). Urinary tract infections in pregnancy. Current Opinion in Urology.11:55-59

Petty, N. K., Ben-Zakour, N. L., Stanton-Cook, M., Skippington, E., Totsika, M., Forde, B. M., Phan, M. D., Gomes, M. D., Peters, K. M., Davies, M., Rogers, B. A., Dougan, G., Rodriguez-Bano, J., Pascual, A., Pitout, J. D., Upton, M., Paterson, D. L., Walsh, T. R., Schembri, M. A. and Beatson, S. A. (2014). Global dissemination of a multidrug resistant Escherichia coli clone. Proc Natl Acad Sci U S A 111: 5694-5699.

Philippon, A., Labia, R. and Jacoby, G. (1989). Extended spectrum beta lactamases. Journal of Antimicrob Agents Chemo.33:1131-6

Rogers, B. A., Sidjabat, H. E. and Paterson, D. L. (2011). Escherichia coli O25b-ST131: a pandemic, multi resistant, communityassociated strain. Journal of Antimicrobial Chemo theraphy. 66: 1-14.

Ruiz, J., Simon, K., Horcajada, J. P., Velasco, M., Barranco, M., Roig, G., MorenoMartinez, A., Martinez, J.A., Jimenez, de Anta T., Mensa, J. and Vila, J. (2002). Differences in virulence factors among clinical isolates of Escherichia coli causing cystitis and pyelonephritis in women and prostatitisin men. Journal of Clinical Microbiology; 40:4445-4449.

Sabir, S., Anjum, A. A., Ijaz, T., Ali, M. A., Khan, M. R. and Nawaz, M. (2014). Isolation and antibiotic susceptibility of $E$. coli from urinary tract infections in a tertiary care hospital. Pak Journal of Medical Science; 30 (2):389-392.

Sire, J. M., Nabeth, P. and Perrier-Gros-Claude, J. D. (2007). Antimicrobial resistance in outpatient Escherichia coli urinary isolates in Dakar, Senegal. Journal of infection in Developing Countries.1:263268.

Sotto, A., De Boever, C. M. and Fabbro-Peray, P. (2001). Risk Factors for Antibioticresistant Escherichia coli isolated from hospitalized patients with urinary tract infections: a prospective study. Journal of Clinical Microbiology.39:438-444.

Swedres- Svarm (2014). Consumption of antibiotics and occurrence of antibiotic resistance
Sweden.2014.http://www.sva.se/globala ssets/redesign2011/pdf/om_sva/publikati oner/swedres_svarm2014.pdf. Accessed 8 June 2017.

Szmolka, A. and Nagy, B. (2013). Multidrug resistant commensal Escherichia coli in animals and its impact for public health. Front Microbiology. 4:258. https: / / doi.org/10.3389/fmicb.2013.0025 8 PMID: 24027562

Thenmozhi, S., Rajeswari, P., Suresh, K. B. T., Saipriyanga, V. and Kalpana, M. (2014). Multi-Drug Resistant Patterns of Biofilm Forming Aeromonas Hydrophila from Urine Samples International Journal of Pharmaceutical Sciences and Research. In: Intentional Journal of Pharmaceutical Sciences Research. 5(7): pp. 2908-2918. [Internet]. [cited 5 Jul 2019]. Available: http: / /ijpsr.com/bft-article/multi-drugresistant-patterns-of-biofilmformingaeromonas-hydrophila-from-urinesamples/?view=fulltext

Walsh, C. (2003). Where will new antibiotics come from? Nat Rev Microbiol 1: 65-70.

Warren, J. W., Abrutyn, E., Hebel, J. R., Johnson, J. R., Schaeffer, A. J. and Stamm, W. E. (1999). Guidelines for antimicrobial treatment of uncomplicated acute bacterial cystitis and acute pyelonephritis in women. Clinical Infectious Diseases, 29(4), 745-759.

Wenzel, R. P., Bearman, G. and Edmond, M. B. (2008). Screening for MRSA: a flawed hospital infection control intervention. Infectious Control Hospital Epidemiology 29: 1012-1018.

Williams, N. S., Bulstrode, C. J. K. and O'Connell, P. R. O. (2008), editors. 25th ed. London: United Kingdom: Edward Arnold Publishers; Bailey \& Love's Short Practice of Surgery.;1329-30.

Williamson, D. A., Lim, A., Wiles, S., Roberts, S. A. and Freeman, J. T. (2013). Population-based incidence and comparative demographics of communityassociated and healthcare-associated Escherichia coli bloodstream infection in Auckland, New Zealand, 2005-2011. BMC Infect Dis 13: 385-392.

Zhang, L. and Foxman, B. (2003). Molecular epidemiology of Escherichia coli mediated urinary tract infections. Frontiers in Bioscience;8: e235-e244.

Zhuge, X., Ji, Y., Tang, F., Sun, Y., Jiang, M. and Hu, W. (2017). Population Structure and Antimicrobial Resistance Traits of Avian-origin. PMID: 31059196. 